\title{
Electrospray Ionization Mass Spectrometric Study of Encapsulation of Amino Acids by Cyclodextrins
}

\author{
Ragulan Ramanathan and Laszlo Prokai \\ Center for Drug Discovery, College of Pharmacy, University of Florida, Gainesville, Florida, USA
}

\begin{abstract}
Electrospray ionization (ESI) mass spectrometry has been used to study inclusion (host-guest) complexes of cyclodextrins (CDs) with amino acids. Host-guest complexes formed in solution are stable for characterization by ESI mass spectrometry: The relative abundances and the stoichiometry of the complexes formed in solution can, thus, be determined in the gas phase. The studies verified that $\beta$ - and $\gamma$-cyclodextrin better accommodate protonated amino acids than $\alpha$-cyclodextrin, and that chemically modified cyclodextrins such as heptakis(2,6-di-O-methyl)- $\beta$-cyclodextrin (DM- $\beta$-CD) may show profound improvement in complexation. The preferential formation of DM- $\beta$-CD-aromatic amino acid over DM- $\beta$ $\mathrm{CD}$-aliphatic amino acid complexes is confirmed by the experiments, and the relative gas-phase stabilities determined by repeller-collimator collision-induced dissociation show an identical trend to the complexation in solution. Although molecular mechanics studies also may predict the encapsulation preference of protonated amino acids by cyclodextrins, only small differences in the total complexation energies are obtained because of the inability of the calculations to consider hydrophobic interactions. An experimental approach based on ESI mass spectrometry is, therefore, more reliable in predicting host-guest interactions that involve cyclodextrins and amino acids than the theoretical calculations that employ molecular mechanics models. (J Am Soc Mass Spectrom 1995, 6, 866-871)
\end{abstract}

$\mathrm{I}$ nclusion (host-guest) complexes are formed by the entrapment of guest species (ions-molecules) by a host molecule such as a crown ether, calixarene, cyclophane, or cyclodextrin (CD). Host-guest complexation does not involve covalent bonding, but a combination of various other (hydrogen bonding, electrostatic, hydrophobic, and van der Waals) interactions. The ability of $C D s$ to hold various guest molecules in a hydrophobic cavity makes them important excipients in many areas (food, pharmaceutics, cosmetics and agriculture) [1]. CDs commonly are used to improve the solubility, stability, and bioavailability of drugs by forming inclusion complexes [2]. Cyclodextrins are cyclic oligosaccharides that contain six, seven, or eight glucopyranose units, called $\alpha-, \beta$-, and $\gamma-C D$, respectively. The physical structure of CDs resembles a truncated cone with a hollow cylindrical cavity in the center [3].

Mass spectrometry has had limited contribution to studies of $C D$ inclusion complexes, although soft ionization methods such as fast-atom bombardment (FAB), ionspray, and electrospray produce $C D$ complexes in the gas phase [4-9]. Recently, noncovalent complexes that reveal enzyme-substrate, receptor-ligand, anti-

Address reprint requests to Dr. Laszlo Prokai, Center for Drug Discovery, University of Florida, P.O. Box 100497, Gainesville, FL 326100497.

(C) 1995 American Society for Mass Spectrometry $1044-0305 / 95 / \$ 9.50$

SSDI 1044-0305(95)00482-S body-antigen, protein-cofactor, and other macromolecular host-guest interactions that exist in solution have been studied successfully via spray ionization methods (electrospray and ionspray) [10,11].

We have investigated inclusion complexes of CDs generated from solution by electrospray ionization (ESI) mass spectrometry. Amino acids (L-tryptophan, L-phenylalanine, L-tyrosine, and L-valine) were selected as model guest molecules. Capacity factors measured by high-performance liquid chromatography (HPLC) have shown the complex stability to increase in the order of tyrosine (Tyr), phenylalanine (Phe), and tryptophan (Trp) [12]. However, CD complexes of aliphatic amino acids such as valine (Val) are less stable than those of the aromatic amino acids. In addition to studies on the relationship of solution equilibria and ESI mass spectra, collision-induced dissociation (CID) also was used to probe the relative stabilities of these complexes in the gas-phase.

\section{Experimental}

\section{Materials}

All L-amino acids, $\alpha-C D, \beta-C D, \gamma-C D$, and DM- $\beta-C D$ were purchased from Sigma Chemical Company (St. Louis, $\mathrm{MO}$ ) as free bases. The CDs were dissolved in $50 / 50(\mathrm{v} / \mathrm{v})$ methanol/water mixture and the amino 
acids were dissolved in 45/45/10 (v/v) methanol/ water/acetic acid solution. Aliquots of these stock solutions were mixed and used as samples.

\section{Electrospray Ionization Mass Spectrometry}

All experiments were done by using a Vestec 200 ES single quadrupole mass spectrometer (PerSeptive Biosystems, Vestec Mass Spectrometry Products, Houston, TX) equipped with an ESI source [13]. Electrospray ionization was achieved by application of a potential of 2-2.5 kV to a flat-tipped (120- $\mu \mathrm{m}$ i.d.) stainless steel needle. A $100-\mu \mathrm{L}$ gas-tight syringe (Hamilton, Nevada) connected to the spray needle via a $50-\mathrm{cm} \times 100-\mu \mathrm{m}$-i.d. fused silica tubing delivered the sample solution at $2-5 \mu \mathrm{L} / \mathrm{min}$ flow rate via a syringe pump (Sage Instruments, Cambridge, MA).

A flat stainless steel plate with a $0.4-\mathrm{mm}$ orifice functioned as the counterelectrode (nozzle). The distance between the spray needle and the nozzle was $1 \mathrm{~cm}$. The total ESI current was measured at the nozzle and maintained between 0.15 and $0.2 \mu \mathrm{A}$. The source block was heated to $250^{\circ} \mathrm{C}$ to reach $55-60^{\circ} \mathrm{C}$ in the spray chamber. The collimator was held at a potential of $10 \mathrm{~V}$ [13]. The repeller (a skimmer with a $0.6-\mathrm{mm}$ orifice positioned behind the nozzle to create the first differentially pumped region) potential was maintained at 12-15 V under normal operating conditions, and increased above $15 \mathrm{~V}$ (up to $225 \mathrm{~V}$ ) to achieve CID in the repeller-collimator region. Assuming that the laboratory collision energy $\left(E_{\text {lab }}\right.$ ) is the repeller-collimator potential difference $(\Delta V)$ and that air functions as the collision (target) gas, the center-of-mass collision energy $E_{\mathrm{cm}}$ for CID of the singly charged ions involved in the study was estimated as follows:

$$
E_{\mathrm{cm}}=\Delta V \frac{m_{\mathrm{T}}}{m_{\mathrm{p}}+m_{\mathrm{T}}}
$$

where $m_{\mathrm{T}}$ is the relative mass of the target (collision) gas and $m_{\mathrm{p}}$ is the mass of the projectile (precursor) ion. During operation, the pressure in the repellercollimator and the analyzer regions was $0.14-0.2$ and 6-8 $\times 10^{-6}$ torr, respectively.

To eliminate variables associated with sample preparation and electrospray ionization [14-18], solution $\mathrm{pH}$, solvent composition, spray chamber temperature, sample temperature, nozzle potential, and spray needle potential were identical for all experiments. A Vector/Two data system (Teknivent, St. Louis, MO) was used to control the mass spectrometer and acquire mass spectra between $\mathrm{m} / \mathrm{z} 20$ to 2000 at a scan speed of $3 \mathrm{~ms} / \mathrm{u}$.

\section{Computational Studies}

Calculations were done by HyperChem (Hypercube, Inc., Waterloo, Ontario, Canada), a personal computerbased molecular modeling program. Molecular models for CDs were built from the $x$-ray crystallographic data [19] by attaching hydrogens, whose coordinates are not contained in the $x$-ray data file, to the heavy atoms ( $C$ and $\mathrm{O}$ ) by the model builder of HyperChem. The side chain of the amino acids was then aligned into the cavity to obtain starting geometries for the inclusion complexes. Geometry optimizations were done by a conjugate gradient (Polak-Ribiere) method by using the $\mathrm{MM}+$ (an extended MM2 [20]) force field, as implemented in the HyperChem program. Because $x$ ray crystallographic data were not available for $D M-\beta$ $C D$, semiempirical (AM1) quantum chemical calculation on 2,6-dimethyl- $\alpha$-D-glucopyranose as a model for the CD building blocks $[21,22]$ was done to estimate atomic charges. AM1 calculations also were used to estimate atomic charges of the protonated amino acids. To remove bias imposed by the model building, simulated annealing (equilibration at $300 \mathrm{~K}$ for $10 \mathrm{ps,} \mathrm{then}$ cooling to $0 \mathrm{~K}$ in $2 \mathrm{ps}$ ) based on molecular dynamics (MD) was used before the subsequent geometry optimization and calculation of the potential energy $(E)$ of the DM- $\beta-C D$ inclusion complexes. The MD also used the $\mathrm{MM}+$ force field, and was done with a 0.5 -fs step size. A longer (200-ps) MD simulation, after the 12-ps simulated annealing, at $500 \mathrm{~K}$ with 1 -fs step size [23] was unsuccessful because the merged molecules started to fall apart as the run progressed [24]. Each simulation took about 3-4 days on an IBM-compatible $486 / 33-\mathrm{MHz}$ computer. This computational approach may not yield global minima for the cyclodextrin complexes because of the large number of local minima in such high dimensional systems and the incomplete sampling by the short MD simulations. Nevertheless, the energy values obtained by simulated annealing are used to estimate host-guest interactions involving CDs [24]. The total complexation energy $\Delta E$, was calculated as

$$
\Delta E=E_{\text {complex }}-\left(E_{\text {host }}+E_{\text {guest }}\right)
$$

where $E_{\text {complex }}, E_{\text {host }}$, and $E_{\text {guest }}$ are the potential energy of the inclusion complex, host (CD), and guest (protonated amino acid), respectively. The potential energy $E$ obtained from MM calculations is a measure of intramolecular strain in a hypothetical situation. By itself, $E$ has no physical meaning. Therefore, $\Delta E$ may only reflect trends in host-guest complexation.

\section{Results and Discussion}

Various cyclodextrin-protonated amino acid complexes $\left[(\mathrm{CD})-(\mathrm{AA}) \mathrm{H}^{+}\right]$can be studied easily by ESI mass spectrometry. Several studies have shown that at lower repeller-collimator or capillary-skimmer potential difference, the ESI mass spectra reflect the ions formed or present in solution [25]. Similarly, host-guest complexes measured in the gas phase with $\Delta V$ of $2 \mathrm{~V}$ are likely to be the stable complexes formed in solution. To study the complexation preference that involves 
different hosts, we carried out ESI experiments by using excess CDs to the given guest molecule. In turn, the interaction of different protonated amino acids with a particular $C D$ was compared by electrospraying solutions that contained molar excess of the guest molecules. The competing species were present in equimolar concentrations that allowed direct comparisons based on mass spectra. However, ESI efficiencies also may be compound dependent. In our studies, the complexes that are compared are similar enough that differences in their ESI efficiencies should not be large, and their relative ion intensities are presumed to correlate with relative concentrations in solution.

We have characterized the interaction of protonated tryptophan $\left[(\operatorname{Trp}) \mathrm{H}^{+}\right]$with $\mathrm{CDs}$, with emphasis on the effects of varying cavity diameters within the $C D$ series: $\alpha-C D(4.7-5.3 \AA), \beta-C D(6.0-6.5 \AA)$, and $\gamma-C D$ $(7.5-8.3 \AA$ ) [3]. A mass spectrum shown in Figure 1 is obtained by electrospraying equimolar mixtures of $\alpha$-, $\beta$-, and $\gamma$-CDs $\left(1.0 \times 10^{-4} \mathrm{M}\right)$ with $(\operatorname{Trp}) \mathrm{H}^{+}(1.0 \times$ $10^{-5} \mathrm{M}$ ). Ions detected at $\mathrm{m} / \mathrm{z} 1178,1340$, and 1502 correspond to $\alpha-\mathrm{CD}-(\operatorname{Trp}) \mathrm{H}^{+}, \beta-\mathrm{CD}-(\operatorname{Trp}) \mathrm{H}^{+}$, and $\gamma$ $\mathrm{CD}-(\operatorname{Trp}) \mathrm{H}^{+}$, respectively. Ions due to inclusion of $\mathrm{Na}^{+}$(an impurity in the solvents and chemicals used) by $\alpha-, \beta-$, and $\gamma-C D s$ are observed at $m / z$ 996, 1158, and 1320 , respectively. The integrated intensity (including the unresolved isotope peaks) of $[\alpha-C D+$ $\mathrm{Na}^{+}(\mathrm{m} / z$ 996) is about $75 \%$ of that of the $(\alpha-$ $\mathrm{CD})-(\mathrm{Trp}) \mathrm{H}^{+}$complex, which shows that a relatively high concentration of free cyclomaltohexaose is present in the solution. However, the relative intensity of the $\mathrm{Na}^{+}$adducts that show the solution concentration of free $\beta-C D(m / z 1158)$ and $\gamma-C D(m / z 1320)$ is 30 and $20 \%$, respectively, compared with that of the respective $(\operatorname{Trp}) \mathrm{H}^{+}$complexes. The lower concentration of free $\mathrm{CD}$ in the solution is equivalent to a better complexation of the protonated amino acid by the given cyclic oligosaccharide. The trend observed in the ESI mass spectra corroborates, therefore, earlier theoretical studies [26] that concluded that a better match be-

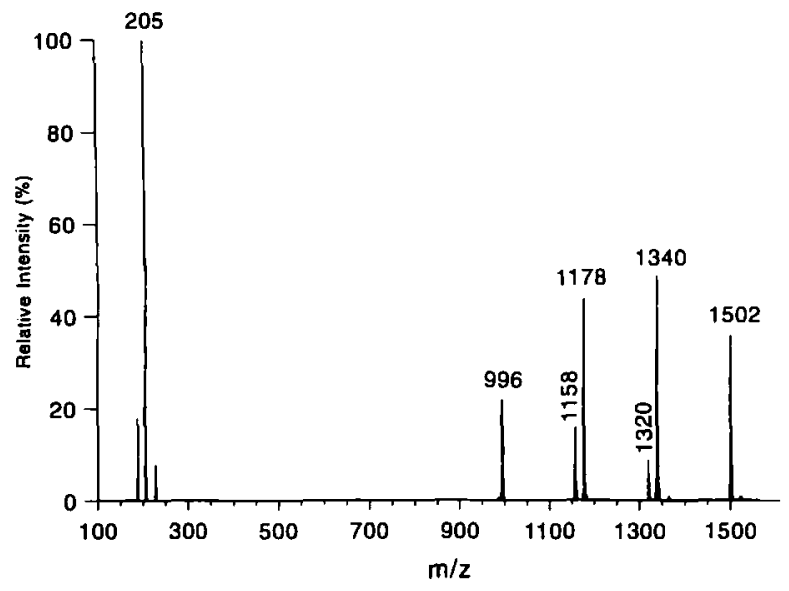

Figure 1. ESI mass spectrum of a solution that contained $(\operatorname{Trp}) \mathrm{H}^{+}\left(1.0 \times 10^{-5} \mathrm{M}\right), \alpha-, \beta$, and $\gamma$-CDs $\left(1.0 \times 10^{-4} \mathrm{M}\right.$ each) at a repeller-collimator potential difference $(\Delta V)$ of $2 \mathrm{~V}$. tween the cavity diameter of the $C D$ and the size of guest molecule increases the net complex stabilization. Although ESI mass spectra show the preference in host-guest interactions among CDs under competitive complexation, estimation of the complexation constants is hampered by the apparent bias in the relative ESI sensitivities of the ions that exist in solution. We used 30-fold excess of $C D$ to amino acid in the spraying solution, but the relative proportion of the amino acid in the ions measured in the ESI mass spectrum was more than that of the CDs.

Figure 2 shows the mass spectrum obtained by ESI of equimolar mixtures of Trp, Phe, Tyr, Val, and $\beta$-CD. (Here, again, a competition exists among the protonated amino acids in solution to form a complex with the weak binding sites in the internal cavity of the cyclomaltoheptaose, as dictated by the respective complexation constants.) Ions that correspond to inclusion of $(\mathrm{Val}) \mathrm{H}^{+}$, (Phe $) \mathrm{H}^{+}$, (Tyr) $\mathrm{H}^{+}$, and $(\mathrm{Trp}) \mathrm{H}^{+}$by $\beta$-CD are detected at 1253, 1301, 1317, and $1340 \mathrm{u}$, respectively (Figure 2 inset). The ESI mass spectrum also shows the presence of uncomplexed $(\mathrm{Val}) \mathrm{H}^{+},(\mathrm{Phe}) \mathrm{H}^{+}$, $(\mathrm{Tyr}) \mathrm{H}^{+}$, and $(\operatorname{Trp}) \mathrm{H}^{+}$at $118,166,182$, and $205 \mathrm{u}$, respectively. The ion at $m / z 1158$, as in Figure 1, is due to the $\mathrm{Na}^{+}$adduct of free $\beta-\mathrm{CD}$, which suggests that ESI mass spectra reflect solution equilibria. $\beta$-CD encapsulates protonated amino acids involved in our study, as shown by the ESI mass spectrum, in the order of $\operatorname{Trp}>$ Phe $>$ Tyr $>$ Val.

The commercially available heptakis(2,6-di-Omethyl) $\beta-C D$ is a mixture that also contains $C D$ with 15,16 , and 17 methyl groups (the nominal mass separation between the peaks is $14 \mathrm{u}$ ). Because the nominal mass difference between (Phe) $\mathrm{H}^{+}$and (Tyr) $\mathrm{H}^{+}$is $16 \mathrm{u}$, we studied their complexation (due to the poor resolution of the quadrupole analyzer above $1000 \mathrm{u}$ ) separately, rather than in competitive experiments, but under the same conditions. Each protonated amino acid appeared in the ESI mass spectra mainly as a complex with $D M-\beta-C D$ (more than $90 \%$ of the normalized total intensity), as opposed to the complexation by $\beta-C D$, under conditions identical to that of Figure 2 . This observation, by itself, may be an indication that the chemically modified $C D$ complexes protonated amino acids better than the natural cyclomaltoheptaose. However, no direct comparison should be made, because complexes of DM- $\beta$-CD also may spray more efficiently than those of the underivatized cyclodextrin.

The relationship of complex formation in solution to the relative ESI intensity of the complex ions has been studied in a series of experiments by variation of the $D M-\beta-C D$ concentration. Figure 3 gives the normalized ion intensities of each amino acid CD complex as the function of DM- $\beta-C D$ concentration (linear versus $\log$ scale [2]). The concentration of amino acid was kept at $5.0 \times 10^{-5} \mathrm{M}$. The normalized intensities of $(\operatorname{Trp}) \mathrm{H}^{+}$, $(\mathrm{Phe}) \mathrm{H}^{+},(\mathrm{Tyr}) \mathrm{H}^{+}$, and $(\mathrm{Val}) \mathrm{H}^{+}$complexes increase from 35 to 97,27 to 95,16 to 94 , and 13 to $92 \%$, 


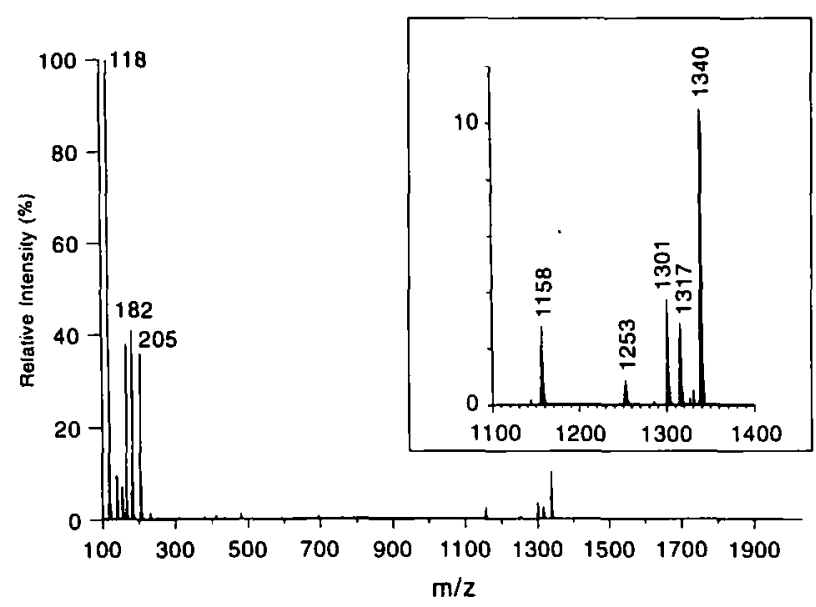

Figure 2. ESI mass spectrum of a solution that contained $($ Val $) \mathrm{H}^{+},(\mathrm{Tyr}) \mathrm{H}^{+},(\mathrm{Phe}) \mathrm{H}^{+}$, and $(\operatorname{Trp}) \mathrm{H}^{+}\left(1.0 \times 10^{-5} \mathrm{M}\right.$ each) and $\beta$-CD $\left(1.0 \times 10^{-5} \mathrm{M}\right)$ at $\Delta V=2 \mathrm{~V}$. The inset shows the expanded region between 1100 and $1400 \mathrm{u}$.

respectively, as the DM- $\beta$-CD concentration increases from $3.7 \times 10^{-8}$ to $7.5 \times 10^{-5} \mathrm{M}$. Between $7.5 \times 10^{-5}$ and $7.5 \times 10^{-4} \mathrm{M}$, the system reaches saturation, where the percentage complexation of protonated amino acids differs only by 1 to $5 \%$. At less than $7.5 \times 10^{-5} \mathrm{M} \mathrm{DM}-\beta-\mathrm{CD}$, the selectivity of the host for protonated amino acids is, however, clearly $(\operatorname{Trp}) \mathrm{H}^{+}>$ (Phe) $\mathrm{H}^{+}>(\mathrm{Tyr}) \mathrm{H}^{+}>(\mathrm{Val}) \mathrm{H}^{+}$. Figure 4 illustrates the mass spectra obtained with $4 \times 10^{-7} \mathrm{M} \mathrm{DM}-\beta-\mathrm{CD}$ and $5 \times 10^{-5} \mathrm{M}$ of $\mathrm{Trp}$ and $\mathrm{Val}$, respectively. $(\mathrm{DM}-\beta-$ CD) $-(\operatorname{Trp}) \mathrm{H}^{+}(m / z 1536+14 m, m=0-3),(\mathrm{DM}-\beta-$ CD) $-(\mathrm{Val}) \mathrm{H}^{+}(m / z 1449+14 m, m=0-3),(\mathrm{DM}-\beta-$ CD) $\mathrm{Na}^{+}(m / z 1354+14 m, m=0-3)$, and the free protonated amino acids $(\mathrm{m} / \mathrm{z} 205$ and 118) can be identified clearly. These studies, again, have shown that selectivity in host-guest interaction may be revealed better at a low percentage complexation of the guest than close to complete binding to the host.

For the studies on the gas-phase stabilities of the DM- $\beta-C D$ inclusion complexes, we selected solution concentrations where $90-95 \%$ complexation of proto-

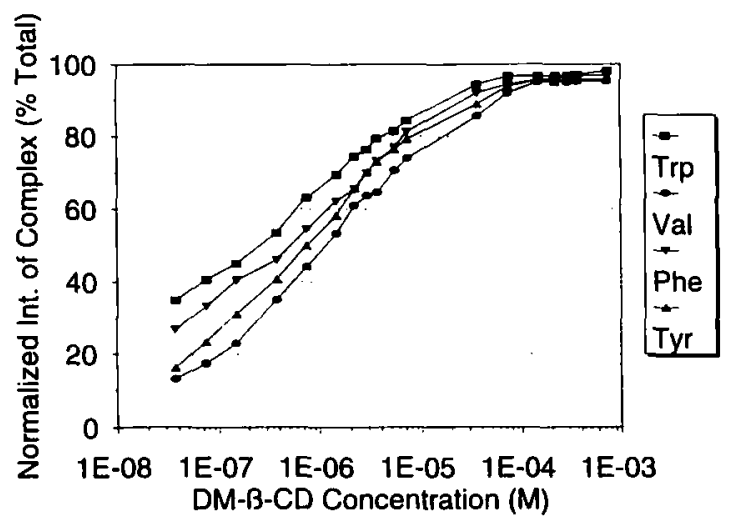

Figure 3. Plot of normalized ion intensities of amino acid complexes as a function of DM- $\beta-C D$ concentration in the sample solution. (The concentration of amino acid is $5.0 \times 10^{-5} \mathrm{M}$.)

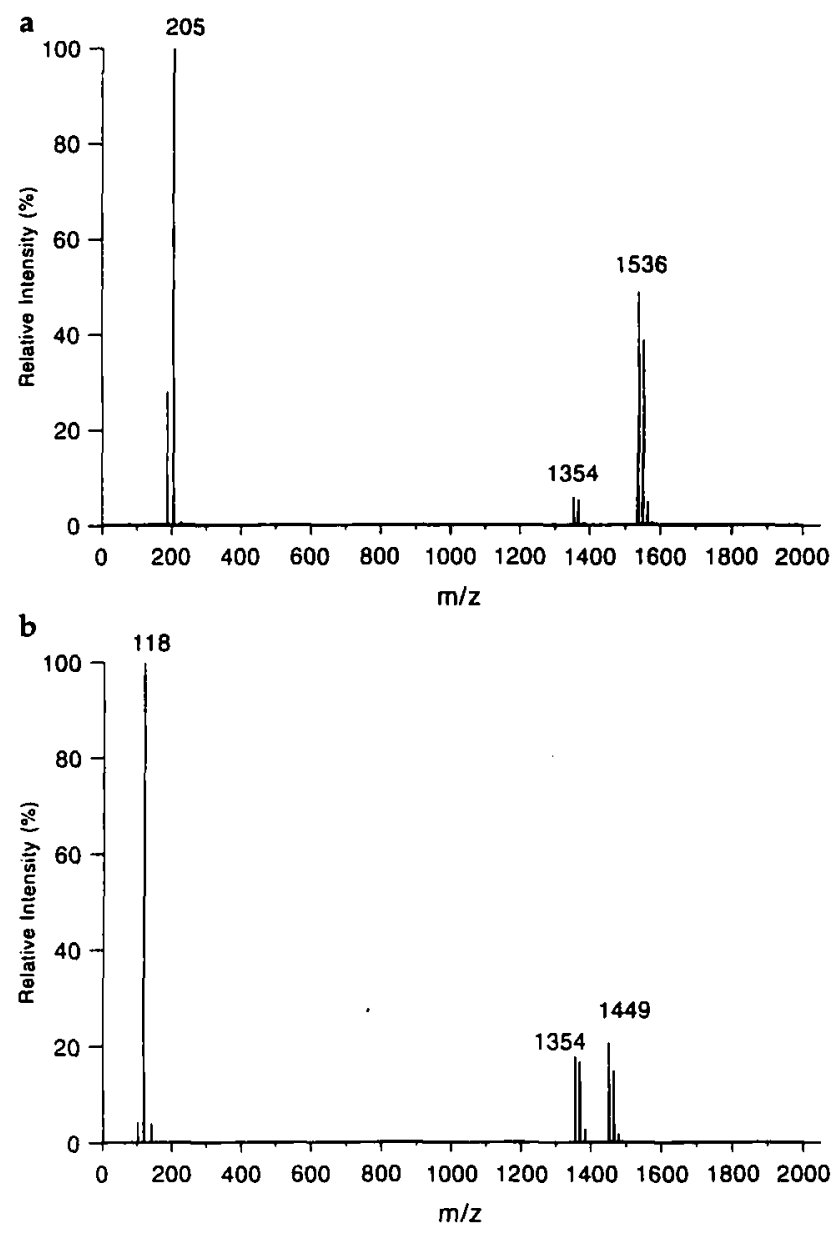

Figure 4. ESI mass spectra $(\Delta V=2 \mathrm{~V})$ that show the encapsulation of (a) (Trp) $\mathrm{H}^{+}$and (b) $(\mathrm{Val}) \mathrm{H}^{+}$by $\mathrm{DM}-\beta-\mathrm{CD}$. (The amino acid and DM- $\beta-C D$ concentration are $5.0 \times 10^{-5}$ and $4 \times 10^{-7} \mathrm{M}$, respectively.)

nated amino acids was achieved. This allowed us to do CID experiments without prior separation of the complexes according to their mass-to-charge ratio (tandem mass spectrometry). Repeller-collimator CID [27] is a convenient method to obtain structural information and relative stabilities of host-guest complexes produced by ESI. A separate repeller-collimator CID experiment was done for each complex to probe relative stabilities and study fragmentation.

The CID threshold of the complexes is around 15-V repeller-collimator potential difference, where the loss of $\left[\left(\mathrm{CH}_{3}\right)_{2} \mathrm{C}_{6} \mathrm{H}_{8} \mathrm{O}_{5}\right]_{n}(n=1$ and 2) units from the protonated host molecule [DM- $\beta-\mathrm{CD}+\mathrm{H}]^{+}$(formed presumably during or after the dissociation of the complex) is observed at $m / z 1142$ and 951 . However, direct loss of the protonated amino acid, such as ( $\operatorname{Trp}) \mathrm{H}^{+}$, from the complex is not predominant. Apparently, a proton transfer occurs during CID from the guest to the host. (Fragmentation of a protonated host requires low $\Delta V$ under repeller-collimator CID [28], and the excess internal energy needed for fragmentation may be acquired along the reaction coordinate upon dissociation of the complex.) As $\Delta V$ is increased 
Table 1. Gas-phase stability of $(D M-\beta-C D)-(A A) H^{+}$complexes under collision-induced dissociation in the repeller-collimator region and total complexation energies obtained by theoretical calculations (molecular mechanics, $\mathrm{MM}+$ )

\begin{tabular}{cccc}
\hline Complex & $\begin{array}{c}E_{\mathrm{cm}} \text { for dissociation } \\
\text { of } 50 \% \text { of the complex } \\
(\mathrm{eV})\end{array}$ & $\begin{array}{c}E_{\mathrm{cm}} \text { for dissociation } \\
\text { of } 100 \% \text { of the complex } \\
(\mathrm{eV})\end{array}$ & $\begin{array}{c}\Delta E \\
(\mathrm{kcal} / \mathrm{mol})\end{array}$ \\
\hline \hline$(\mathrm{DM}-\beta-\mathrm{CD})-(\mathrm{Trp}) \mathrm{H}^{+}$ & 2.90 & $>4.0$ & -67.6 \\
$(\mathrm{DM}-\beta-\mathrm{CD})-(\mathrm{Phe}) \mathrm{H}^{+}$ & 1.13 & 2.1 & -66.6 \\
$(\mathrm{DM}-\beta-\mathrm{CD})-(\mathrm{Tyr}) \mathrm{H}^{+}$ & 1.00 & 1.8 & -64.0 \\
$(\mathrm{DM}-\beta-\mathrm{CD})-(\mathrm{Val}) \mathrm{H}^{+}$ & 0.90 & 1.3 & -61.5 \\
\hline
\end{tabular}

to $40 \mathrm{~V},(\mathrm{DM}-\beta-\mathrm{CD})-(\mathrm{AA}) \mathrm{H}^{+}$ions fragment to yield ions by losses of $\left[\left(\mathrm{CH}_{3}\right)_{2} \mathrm{C}_{6} \mathrm{H}_{8} \mathrm{O}_{5}\right]_{3}(\mathrm{~m} / z$ 761) and $\left[\left(\mathrm{CH}_{3}\right)_{2} \mathrm{C}_{6} \mathrm{H}_{8} \mathrm{O}_{5}\right]_{4}(\mathrm{~m} / z$ 571) from the protonated host molecule. Fragments of the protonated amino acid, such as $\left[(\operatorname{Trp}) \mathrm{H}-\mathrm{NH}_{3}\right]^{+}(m / z$ 188), also appear. Between $\Delta V$ of 65 to $90 \mathrm{~V}$, the loss of $\left[\left(\mathrm{CH}_{3}\right)_{2} \mathrm{C}_{6} \mathrm{H}_{8} \mathrm{O}_{5}\right]_{5}$ $(\mathrm{m} / \mathrm{z} 381)$ units from the host molecule results is the most abundant fragment ion. Increasing the potential difference above $90 \mathrm{~V}$, $\left[\mathrm{DM}-\beta-\mathrm{CD}-\left[\left(\mathrm{CH}_{3}\right)_{2} \mathrm{C}_{6} \mathrm{H}_{8} \mathrm{O}_{5}\right]_{6}\right.$ $\left.-\left(\mathrm{H}_{2} \mathrm{O}\right)_{2}+\mathrm{H}\right]^{+}$at $m / z \quad 155$ is the most abundant, and $\left[\mathrm{DM}-\beta-\mathrm{CD}-\left[\left(\mathrm{CH}_{3}\right)_{2} \mathrm{C}_{6} \mathrm{H}_{8} \mathrm{O}_{5}\right]_{6}-\left(\mathrm{H}_{2} \mathrm{O}\right)+\mathrm{H}\right]^{+}$ and $\left[D M-\beta-C D-\left[\left(\mathrm{CH}_{3}\right)_{2} \mathrm{C}_{6} \mathrm{H}_{8} \mathrm{O}_{5}\right]_{6}+\mathrm{H}\right]^{+}$also are observed at $\mathrm{m} / z 173$ and 191. Stepwise loss of glucopyranose units from DM- $\beta-C D$ was common at higher $\Delta V \mathrm{~s}$ with all $(\mathrm{DM}-\beta-\mathrm{CD})-(\mathrm{AA}) \mathrm{H}^{+}$complexes studied. However, the $E_{\mathrm{cm}} \mathrm{s}$ required to reach $50 \%$ and full dissociation of the complexes vary as shown in Table 1. (DM- $\beta$-CD)-(Val) $\mathrm{H}^{+}$falls apart completely at $E_{\mathrm{cm}}$ of $1.3 \mathrm{eV}$, whereas $(\mathrm{DM}-\beta-\mathrm{CD})-(\operatorname{Trp}) \mathrm{H}^{+}$needs more than $4 \mathrm{eV}$ for complete dissociation.

ESI mass spectrometry on the complexation of amino acids by cyclodextrins has revealed trends similar to a recent solution (HPLC-based) study [12]. In comparison, we also used molecular mechanics (MM) and MD-MM calculations that involved $(\alpha-\mathrm{CD})-(\operatorname{Trp}) \mathrm{H}^{+}$, $(\beta-C D)-(A A) H^{+}, \quad(\gamma-C D)-(\operatorname{Trp}) \mathrm{H}^{+}$, and $(D M-\beta-$ CD)-(AA) $\mathrm{H}^{+}$complexes (in vacuo). The complexation of $(\operatorname{Trp}) \mathrm{H}^{+}$was, indeed, less favored by $\alpha-\mathrm{CD}(\Delta E=$ $-10.5 \mathrm{kcal} / \mathrm{mol})$ than by $\beta-C D(\Delta E=-15.1$ $\mathrm{kcal} / \mathrm{mol})$ and $\gamma \mathrm{CD}(\Delta E=-15.9 \mathrm{kcal} / \mathrm{mol})$. The calculated order of encapsulation of protonated amino acids by $\beta-C D$ is $\operatorname{Trp}(\Delta E=-15.1 \mathrm{kcal} / \mathrm{mol}) \approx$ Phe $(\Delta E=-14.7 \mathrm{kcal} / \mathrm{mol})>\mathrm{Tyr} \quad(\Delta E=-12.8$ $\mathrm{kcal} / \mathrm{mol}) \approx \operatorname{Val}(\Delta E=-12.7 \mathrm{kcal} / \mathrm{mol})$. As shown in Table 1, molecular mechanics also predicted a similar order of complexation for DM- $\beta-C D$. $\Delta E$ for the formation of DM- $\beta$-CD complex of protonated Trp, Phe, Tyr, and Val is $-67.6,-66.6,-64$, and -61.5 $\mathrm{kcal} / \mathrm{mol}$, respectively. Therefore, the spread of $\Delta E$ values is much less than that of the gas-phase stability determined by the CID experiments. The possible origin of the small differences in the calculated total complexation energy is that inclusion of organic guest molecules into CDs is driven partly by hydrophobic interactions not incorporated into MM models. The calculation also predicts so many low-lying conformations of similar energy (less than $2 \mathrm{kcal} / \mathrm{mol}$ difference in $\Delta E$ ) but dissimilar structures that the usefulness of molecular mechanics to predict structure and energetics of host-guest complexes that involve CDs becomes questionable. On the other hand, relative complex stabilities in the gas phase have been revealed clearly by the experimental technique discussed in this paper.

\section{Conclusions}

Host-guest complexation equilibria in solution are reflected by ESI mass spectra obtained at small repeller-collimator potential difference. We have shown that the affinity of $\beta$ - and $\gamma$-cyclodextrins to protonated amino acids is larger than that of $\alpha$-cyclodextrin. The selectivity of $\beta-C D$ and DM- $\beta-C D$ for the protonated amino acids chosen for the study is (Trp) $\mathrm{H}^{+}>(\mathrm{Phe}) \mathrm{H}^{+}>(\mathrm{Tyr}) \mathrm{H}^{+}>(\mathrm{Val}) \mathrm{H}^{+}$. The order of gas-phase stabilities predicted by $\mathrm{MM}$ and $\mathrm{MM} / \mathrm{MD}$ calculations has revealed shortcomings of the theoretical approach. The preferential formation of $C D-$ aromatic amino acid over $C D$-aliphatic amino acid complexes was confirmed in our ESI experiments, but the spread of calculated binding energies $(\Delta E)$ for these complexes was within the error associated with the computational (MM/MD) method. ESI mass spectrometry is, therefore, recommended as an experimental tool to probe $\mathrm{CD}$ complexes.

\section{References}

1. Huber, O.; Szejtli, J. Proceedings of the Fourth International Symposium on Cyclodextrins; Kluwer Academic Publishers: Dordrecht, The Netherlands, 1988.

2. Szejtli, J. Med. Res. Rev. 1994, 14, 353-386.

3. Szejtli, J. Cyclodextrin Technology; Kluwer Academic Publishers: Dordrecht, The Netherlands, 1988.

4. Brinker, U. H.; Buchkremer, R.; Kolodziejczyk, M.; Kupfer, R.; Rosenberg, M.; Poliks, M. D.; Orlando, M.; Gross, M. L. Angew. Chem. Int. Ed. Engl. 1993, 32, 1344-1345.

5. Haskins, N. J.; Saunders, M. R.; Camilleri, P. Rapid Commun. Mass Spectrom. 1994, 8, 423-426.

6. Huang, E. C.; Henion, J. D. Rapid Commun. Mass Spectrom. 1990, 4, 467-471.

7. Ohashi, M.; Kurono, S. In Biological Mass Spectrometry Present and Future; Matsuo, T.; Caprioli, R. M.; Gross, M. L.; Seyama, Y., Eds.; Wiley: New York, 1994; pp 647-653.

8. Selva, A.; Redenti, E.; Zanol, M.; Ventura, P.; Casetta, B. Org. Mass Spectrom. 1993, 28, 983-986. 
9. Sorokine, O.; Leize, E.; Letavernier, J. F.; Ropenga, J.; Van Dorsselaer, A. Proceedings of the 40th ASMS Conference on Mass Spectrometry and Allied Topics; Washington, DC, 1992; PP $1645-1646$.

10. Li, Y. T.; Hsieh, Y. L.; Henion, J. D.; Ocain, T. D.; Schiehser, G. A.; Ganem, B. J. Am. Chem. Soc. 1994, 116, 7487-7493.

11. Smith, R. D.; Light-Wahl, K. /. Biol. Mass Spectrom. 1993, 22, 493-501.

12. Corradini, R.; Dossene, A.; Impellizeri, G.; Maccarone, G.; Marchelli, R.; Rizzarelly, E.; Sartor, G.; Vecchio, G. J. Am. Chem. Soc. 1994, 116, 10267-10274.

13. Allen, M. H.; Vestal, M. L. J. Am. Soc. Mass Spectrom. 1992, 3, 18-26.

14. Mirza, U. A.; Chait, B. T. Anal. Chem. 1994, 66, 2898-2904.

15. Le Blanc, J. C. Y.; Beuchemin, D.; Siu, K. W. M.; Guevremont, R.; Berman, S. S. Org. Mass Spectrom. 1991, 26, 831-839.

16. Guevremont, R.; Siu, K. W. M.; LeBlanc, J. C. Y.; Berman, S. S. 1. Am. Soc. Mass Spectrom. 1992, 3, 216-224.

17. Siu, K. W. M.; Guevremont, R.; Le Blanc, J. C. Y.; O' Brien, R. T.; Berman, S. S. Org. Mass Spectrom. 1993, 28, 579-584.
18. Wang, G.; Cole, R. B. Org. Mass Spectrom. 1994, 29, 419-427.

19. Chacko, K. K.; Saenger, W. J. Am. Chem. Soc. 1981, 103, 1708-1711.

20. Alinger, N. L.; Yuh, Y. H. Quantum Chemistry Program Exchange, Program 395, Bloomington, Indiana, 1991.

21. Brewster, M. E.; Huang, M.; Pop, E.; Pitha, J.; Dewar, M. J. S.; Kaminsky, J. J.; Bodor, N. Carbohydrate Res. 1993, 242, 53-67.

22. Bako, I.; Jicsinszky, L. Proceedings of the 7 th International Cyclodextrin Conference; Tokyo, Japan, 1994; pp 129-133.

23. Sun, Y.; Kollman, P. A. J. Comput. Chem. 1992, 13, 33-40.

24. Ton, W.-Q.; Lach, J. L.; Chin, T.-F.; Guillory, J. K. Pharm. Res. 1991, 8, 1307-1312.

25. Xu, X.; Nolan, S. P.; Cole, R. B. Anal. Chem. 1994, 66, 119-125.

26. Pang, L.; Whitehead, M. A. Supramol. Chem. 1992, 1, 81-92.

27. Loo, J. A.; Udseth, H. R.; Smith, R. D. Biomed. Environ. Mass Spectrom. 1988, 17, 411-418.

28. Prokai, L.; Brewster, M. E.; Bodor, N. Proceedings of the 40 th ASMS Conference on Mass Spectrometry and Allied Topics; Washington, DC, 1992; pp 18-19. 